\title{
Intensity of free radical processes in the leaves of arboreal plants under act of industrial dust borne extracts
}

\author{
Olga Piskova - Vitalii Gryshko \\ Plant physiology and soil biology department, Kryvyi Rig Botanic Garden of the National academy of sciences of Ukraine, \\ Ukraine, Kryvyi Rig, Marshak st., 50, e-mail:vit.grishko@rambler.ru
}

Keywords: Populus bolleana Lauche, Populus italica (Du Roi) Moench, Picea pungens Engelm, Sorbus aucuparia L., Acer negundo L., Aesculus hippocastanum L., Betula pendula Roth, Tilia cordata Mill., speciesspecific accumulation, peroxidation processes, TBA-active products

\section{SUMMARY}

The influence of industrial pollutants on the intensity of lipid peroxidation in the assimilatory organs of arboreal plant was investigated. The differential changes of the probed indexes are set depending on the species. Information is got can testify to participation of lipid peroxidation products in forming of reactions-answers of arboreal plants on influence of industrial dust borne extract with content of heavy metals. Determination of level and rates of accumulation of $\mathrm{Zn}, \mathrm{Ni}, \mathrm{Pb}$ and $\mathrm{Cd}$, in the leaves of arboreal plants in the conditions of different contamination level allowed to take species to two groups. To the first (phytoextraction potential exceeds a base-line level in 10 times) belong Populus bolleana Lauche, P. italica (Du Roi) Moench, Picea pungens Engelm and Sorbus aucuparia L. To the second (exceeds a base-line level from 5 to 10 times) belong Acer negundo L., Aesculus hippocastanum L., Betula pendula Roth and Tilia cordata Mill. The most substantial increase of peroxidation secondary product content (more than in 2.5 times) is peculiar for B. pendula, A. hippocastanum and P. pungens Engelm., that well conforms to the rates of heavy metals translocation, it has however species-specific character.

\section{INTRODUCTION}

Anthropogenic contamination of region in high-urbanized ecosystems results to varied violations of living organism functioning, and above all things plants. Damages show up in changing of anatomical, morphological, physiological and biochemical indexes, which reduce them decorative qualities and biological stability. After the entrance volumes to landscapes heavy metals among, which $\mathrm{Zn}, \mathrm{Pb}, \mathrm{Cd}$ and $\mathrm{Ni}$, have a loan of a leading value and more intensive in all engaged in a biogeochemical rotation (Briat- Lebrun,1999). Among the effects of toxic influence this pollutants on plant organisms displacement of prooxidative-antioxidative equilibrium comes into the special notice in the side of intensification of lipid peroxidation (Bishnoi et al.,1993; Lichtanthaler,1998; Naoharu et al., 2003; Tang - Xi, 2002), in fact exactly activation of lipids peroxidation processes - one of key links between the action of a stress factor and realization of protective reactions of organism (Finkel-Holbrook, 2000; Wang, 2004; Karperts-Kolupaev, 2008).

Coming from that lipid peroxidation products are the determination indexes of character and intensity of a heavy metals stress on living organisms, the purpose of our work was to probe the features of $\mathrm{Zn}, \mathrm{Pb}, \mathrm{Cd}$ and $\mathrm{Ni}$ accumulation and dynamics of lipid peroxidation process changes, in the assimilatory agent of arboreal plants at industrial terms.

\section{MATERIALS AND METHODS}

The objects of researche were Populus bolleana Lauche, P. italica (Du Roi) Moench, Picea pungens Engelm., Acer negundo L., Tilia cordata Mill., Sorbus aucuparia L., Betula pendula Roth, Aesculus hippocastanum L., that grow on industrial ground «Red Lead Factory» LTD (in the zone of strong and weak contamination) and in the arboretum of the Kryvyi Rig Botanic Garden of the National Academy of Sciences of Ukraine, which is accepted for conditional control. From ten trees of every species leaves were taken away in the phases of complete isolation of leave (pine-needles) and completion of their growth.

The content of pollutants in plant material was determined on the atomic-adsorption spectrophotometer after the methods accepted in general lines (Feldman, 1974). The indexes of intertissue contamination expected after Kamishnikov (2000). The degree of lipid peroxidation development was estimated after content of TBA-active products determinations of which conducted on a spectrophotometer CF-2000 (Russia) after the generally accepted method (Kamishnikov, 2000). Protein content in plant tissues was determined after the method of Greenberg (Greenberg-Gaddoc,1982).

Experiments conducted in 3-repetition with biological and analytical methods. The statistical processing of experimental data was conducted after the generally accepted methods of self-reactance statistics at $95 \%$ levels of meaningfulness after Dospekhov (1985). On figures and in tables the average results and their standard deviations are shown. 


\section{RESULTS AND DISCUSSION}

Comparative study was made regarding the content of heavy metals in the assimilatory agent of arboreal plants on both phases of leaf (pine-needles) morphogenesis in control and at of technogen exposes at different species and allows to talk about the certain species-specific accumulation of heavy metals.

According to the analysis of pollutant content contained in plants to the arboretum of the Kryvyi Rig Botanic Garden of the National Academy of Sciences of Ukraine (control) in the phase of complete isolation of leaf is more intensive accumulated in the leaves of Acer negundo L., while in the Populus bolleana Lauche, P. italica (Du Roi) Moench and Tilia cordata Mill. on 36-45\% less (table 1.). In the assimilatory agent of Sorbus aucuparia L., Picea pungens Engelm., and Aesculus hippocastanum L. under the conditions heavy metal content was in 3.3-5.5 times less than, at the Acer negundo L. It is interesting to note, that in this phase in the leaves of Aesculus hippocastanum $\mathrm{L}$. also least $\mathrm{Ni}$ and $\mathrm{Pb}$ was accumulated. In the Populus bolleana Lauche, P. italica (Du Roi) Moench and Betula pendula Roth content of the Ni was higher almost in 20 times by comparison to the inter-tissue contamination index (ICI) of Aesculus hippocastanum L. The high level of accumulation of $\mathrm{Pb}$ (from 1.34 to $1.54 \mathrm{mg} \mathrm{kg}^{-1}$ of fresh weight) in the phase of complete isolation of leaves (pine-needles) is fixed at a Tilia cordata Mill., Acer negundo L. and Sorbus aucuparia L. The table of cadmium contents in the assimilatory agent of most species moved between 0.02 to $0.05 \mathrm{mg} \mathrm{kg}^{-1}$ of fresh weight.

The analytical results of phytotoxicity index are presented in a table testify that the most of all of investigational metals in the leaves of arboreal plants accumulated in the area of strong contamination. The greatest quantity of zinc accumulation which belongs to the class of high-dangerous elements (Balyuk et al., 2004) was found in the phase of complete isolation of leave where characteristic for a Sorbus aucuparia L. (ICI > 30). Populus bolleana Lauche and P. italica (Du Roi) Moench had considerably less rates of this metal accumulation (ICI from 9.0 to 12.6), while at other species of arboreal plants the inter-tissue contamination index did not exceed 3.2. The similar tendency of specific composition was observed in the zone of weak contamination.

In both industrial affected zones sufficiently high values of inter-tissue contamination index of leaves (ICI > 20) were observed in the phase of complete isolation it was characteristic for a cadmium and nickel. The order Regarding both the absolute and after relative indexes, in the order of accumulation the first most contained was the pine-needle of Picea pungens Engelm., while second on absolute indexes - at Populus bolleana Lauche, $P$. italica (Du Roi) Moench and Aesculus hippocastanum L., and after the rates of accumulation - only in Aesculus hippocastanum L. Processes of absorption and translocation to the leaves of $\mathrm{Pb}$ in the phase of complete isolation were the least, as compared to other heavy metals. The values of ICI fluctuated from 3.3 (Populus bolleana Lauche) to 1.2 (Picea pungens Engelm.).

Where as in the phase of completion of leave growth the temps of $\mathrm{Pb}$ accumulation grew almost in 3 times, in compared to the above-described phase (Table 1.). Thus, both on absolute and after relative, indexes the high level accumulations of this metal are inherent Populus bolleana Lauche, P. italica (Du Roi) Moench and Acer negundo L. (6.69 - $11.64 \mathrm{mg} \mathrm{kg}^{-1}$ fresh weight).

In the phase of completion of leave growth among metals investigated zinc had the most often translocated. We have to note that to the group of arboreal plants high this heavy metal content concert Populus bolleana Lauche, P. italica (Du Roi) Moench and Sorbus aucuparia L. The high values of inter-tissue index of contamination of these species have at the same time (in 5.4-10 times more than at other species).

The greatest intensity of cadmium accumulation in the conditions of strong contamination area is observed at Picea pungens Engelm (the value of inter-tissue contamination index of pine-needle in 1.8-3.2 times exceeds the index than other species). Together with it at Populus italica (Du Roi) Moench and Betula pendula Roth, the level of cadmium in an assimilatory agent fluctuated from 0.54 to $0.62 \mathrm{mg} \mathrm{kg}^{-1}$ of fresh weight, it is $1.6-2.6$ times exceed the cadmium content than other species of arboreal plants.

It worth noticing, that for leafy arboreal plants there is common tendency in relation to the maximal accumulation of certain heavy metals on the areas of strong contamination zone compared to the low contamination zone during the research period. So, for example, in the plants leaves of the first zone during two phases of morphogenesis 1.4-3 times more cadmium accumulated in the leaves than in the second zone.

Similar tendency was experienced after the inter-tissue contamination index of leaves.

Concerning the nickel and zinc content, the above-mentioned index value in the phase of leaf isolation of Acer negundo L. in the conditions of strong contamination zone was from 3.77 to 12.62 , while in the weak contamination zone it was only between 1.27 and 3.44 at the .

On the basis of $\mathrm{Zn}, \mathrm{Ni}, \mathrm{Pb}$ and $\mathrm{Cd}$ accumulation level and determination the assimilatory agent of arboreal plants in the conditions of different contamination level, the species can be divided into two groups. To the first group has the greatest phyto-extraction potential of most heavy metals (exceeds the base level in 10 times), belongs Populus bolleana Lauche, P. italica (Du Roi) Moench, Picea pungens Engelm and Sorbus aucuparia L. To the second group has the middle accumulation level (exceeds the base level from 5 to 10 times), belongs Acer negundo L., Aesculus hippocastanum L., Betula pendula Roth and Tilia cordata Mill.

The toxic action of the most heavy metals causes oxidative stress development and accompanied varied alterations of plant metabolism, conditioned both direct membrane lipid peroxidation, and accumulation of peroxidation product and their co-operation, with cellular macromolecules. According to studies the finished free-radical reactions products, in particular TBA-active products, including malonyl dyaldehyde, which at co- 
operating with proteins, amino acid, nucleic acids, lipids can form connection, so called «pigments of senescence» (Finkel-Holbrook, 2000; Kosyk et al., 2006; Wang, 2004).

Table1.

Content of some heavy metals in the leaves of arboreal plants $\left(\mathrm{mg} \mathrm{kg}^{-1}\right.$ of fresh weight)

\begin{tabular}{|c|c|c|c|c|c|c|c|c|}
\hline & \multicolumn{2}{|c|}{$\mathrm{Zn}$} & \multicolumn{2}{|c|}{$\mathrm{Ni}$} & \multicolumn{2}{|c|}{$\mathrm{Pb}$} & \multicolumn{2}{|c|}{$\mathrm{Cd}$} \\
\hline & $\mathrm{M} \pm \mathrm{m}$ & ICI & $\mathrm{M} \pm \mathrm{m}$ & ICI & $\mathrm{M} \pm \mathrm{m}$ & ICI & $\mathrm{M} \pm \mathrm{m}$ & ICI \\
\hline \multicolumn{9}{|c|}{ Populus bolleana Lauche } \\
\hline Control & $\frac{0.52 \pm 0.01}{0.70 \pm 0.01}$ & - & $\frac{1.05 \pm 0.06}{1.55 \pm 0.02}$ & - & $\frac{0.73 \pm 0.01}{0.93 \pm 0.03}$ & - & $\frac{0.03 \pm 0.00}{0.05 \pm 0.00}$ & - \\
\hline $\begin{array}{l}\text { Zone of strong } \\
\text { contamination }\end{array}$ & $\begin{array}{l}\frac{4.70 \pm 0.18}{*} \\
\frac{*}{6.97 \pm 0.04} \\
\quad *\end{array}$ & $\frac{9.03}{9.97}$ & $\begin{array}{l}\frac{2.54 \pm 0.04}{*} \\
\frac{*}{2.73 \pm 0.01} \\
\quad *\end{array}$ & $\frac{2.41}{1.77}$ & $\frac{2.39 \pm 0.09 *}{6.96 \pm 0.10 *}$ & $\begin{array}{l}\underline{3.3}^{\underline{3.3}} \\
2^{7.5} \\
\end{array}$ & $\begin{array}{l}\frac{0.18 \pm 0.02}{*} \\
\frac{*}{0.24 \pm 0.00} \\
*\end{array}$ & $\frac{6.01}{4.80}$ \\
\hline $\begin{array}{l}\text { Zone of weak } \\
\text { contamination }\end{array}$ & $\begin{array}{l}\frac{0.74 \pm 0.08}{*} \\
\frac{*}{6.97 \pm 0.04} \\
\quad *\end{array}$ & $\frac{1.42}{2.69}$ & $\begin{array}{l}\frac{1.92 \pm 0.03}{*} \\
\frac{*}{2.00 \pm 0.01} \\
*\end{array}$ & $\frac{1.82}{1.29}$ & $\frac{1.35 \pm 0.07 *}{2.14 \pm 0.08 *}$ & $\begin{array}{l}\underline{1.8} \\
\underline{6} \\
2.3 \\
1\end{array}$ & $\begin{array}{l}\frac{0.06 \pm 0.00}{*} \\
\frac{*}{0.09 \pm 0.01} \\
\quad *\end{array}$ & $\frac{1.96}{1.77}$ \\
\hline \multicolumn{9}{|c|}{ Populus italica (Du Roi) Moench } \\
\hline Control & $\frac{0.46 \pm 0.02}{0.45 \pm 0.00}$ & - & $\frac{0.72 \pm 0.08}{0.69 \pm 0.01}$ & - & $\frac{0.82 \pm 0.03}{1.42 \pm 0.05}$ & - & $\frac{0.05 \pm 0.00}{0.06 \pm 0.00}$ & - \\
\hline $\begin{array}{l}\text { Zone of strong } \\
\text { contamination }\end{array}$ & $\begin{array}{l}\frac{5.77 \pm 0.09}{*} \\
\frac{*}{10.44 \pm 0.1} \\
5^{*}\end{array}$ & $\begin{array}{l}\frac{12.6}{2} \\
23.0 \\
7\end{array}$ & $\begin{array}{l}\frac{2.73 \pm 0.06}{*} \\
\frac{*}{4.03 \pm 0.11} \\
\quad *\end{array}$ & $\frac{3.77}{5.86}$ & 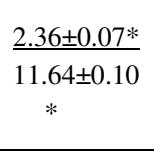 & $\begin{array}{l}\underline{2.8} \\
\underline{7}^{8.1} \\
9 \\
\end{array}$ & $\begin{array}{l}\frac{0.25 \pm 0.01}{*} \\
\frac{*}{0.55 \pm 0.02} \\
*\end{array}$ & $\frac{4.99}{8.65}$ \\
\hline $\begin{array}{l}\text { Zone of weak } \\
\text { contamination }\end{array}$ & $\begin{array}{l}\frac{1.57 \pm 0.09}{*} \\
\frac{*}{4.29 \pm 0.05} \\
*\end{array}$ & $\frac{3.44}{9.50}$ & $\begin{array}{l}\frac{0.92 \pm 0.01}{*} \\
\frac{*}{1.32 \pm 0.01} \\
*\end{array}$ & $\frac{1.27}{1.92}$ & $\frac{1.06 \pm 0.03 *}{5.33 \pm 0.04 *}$ & $\begin{array}{l}\underline{9}^{\underline{1.2}} \\
3.7 \\
5\end{array}$ & $\begin{array}{l}\frac{0.09 \pm 0.00}{*} \\
\frac{*}{0.18 \pm 0.00} \\
\quad *\end{array}$ & $\frac{1.75}{2.88}$ \\
\hline \multicolumn{9}{|c|}{ Acer negundo L. } \\
\hline Control & $\frac{0.83 \pm 0.05}{1.07 \pm 0.00}$ & - & $\frac{0.36 \pm 0.01}{0.56 \pm 0.01}$ & - & $\frac{0.79 \pm 0.01}{2.22 \pm 0.06}$ & - & $\frac{0.04 \pm 0.00}{0.05 \pm 0.00}$ & 一 \\
\hline $\begin{array}{l}\text { Zone of strong } \\
\text { contamination }\end{array}$ & $\begin{array}{l}\frac{2.63 \pm 0.17}{*} \\
\frac{*}{3.71 \pm 0.09} \\
\quad *\end{array}$ & $\frac{3.16}{3.48}$ & $\begin{array}{l}\frac{1.16 \pm 0.06}{\frac{*}{-}} \\
1.50 \pm 0.01 \\
*\end{array}$ & $\frac{3.23}{2.68}$ & $\frac{2.00 \pm 0.15^{*}}{8.08 \pm 0.12^{*}}$ & $\begin{array}{l}\underline{3}^{2.5} \\
3.6 \\
4\end{array}$ & $\begin{array}{l}\frac{0.10 \pm 0.00}{*} \\
\frac{*}{0.26 \pm 0.01} \\
*\end{array}$ & $\frac{2.26}{5.52}$ \\
\hline $\begin{array}{l}\text { Zone of weak } \\
\text { contamination }\end{array}$ & $\begin{array}{l}\frac{1.64 \pm 0.01}{*} \\
\frac{*}{1.90 \pm 0.04} \\
*\end{array}$ & $\frac{1.97}{1.79}$ & $\begin{array}{l}\frac{0.67 \pm 0.01}{*} \\
\frac{*}{0.74 \pm 0.02} \\
\quad *\end{array}$ & $\frac{1.86}{1.33}$ & $\frac{0.56 \pm 0.03 *}{3.10 \pm 0.04 *}$ & $\begin{array}{l}\underline{0.7}^{\underline{0.7}} \\
0^{1.4} \\
\end{array}$ & $\begin{array}{l}\frac{0.07 \pm 0.00}{*} \\
\frac{*}{0.14 \pm 0.00} \\
\quad *\end{array}$ & $\frac{1.61}{2.99}$ \\
\hline \multicolumn{9}{|c|}{ Picea pungens Engelm } \\
\hline Control & $\frac{0.25 \pm 0.01}{1.01 \pm 0.05}$ & - & $\frac{0.53 \pm 0.01}{0.53 \pm 0.01}$ & - & $\frac{1.43 \pm 0.03}{1.17 \pm 0.01}$ & - & $\frac{0.02 \pm 0.00}{0.04 \pm 0.00}$ & - \\
\hline $\begin{array}{l}\text { Zone of strong } \\
\text { contamination }\end{array}$ & $\begin{array}{l}\frac{0.53 \pm 0.04}{*} \\
\frac{*}{2.20 \pm 0.05} \\
\quad *\end{array}$ & $\frac{2.15}{2.18}$ & $\begin{array}{l}\frac{0.61 \pm 0.03}{*} \\
\frac{*}{1.17 \pm 0.04} \\
\quad *\end{array}$ & $\frac{1.16}{2.20}$ & $\frac{1.86 \pm 0.05^{*}}{2.16 \pm 0.06^{*}}$ & $\begin{array}{l}\underline{1.3} \\
\underline{0} \\
5^{1.8} \\
\end{array}$ & $\begin{array}{l}\frac{0.41 \pm 0.01}{*} \\
\frac{*}{0.54 \pm 0.00} \\
\quad *\end{array}$ & $\begin{array}{l}\underline{22.8} \\
\underline{0} \\
15.1 \\
4\end{array}$ \\
\hline \multicolumn{9}{|c|}{ Tilia cordata Mill. } \\
\hline Control & $\frac{0.53 \pm 0.02}{0.79 \pm 0.04}$ & & $\frac{0.26 \pm 0.02}{0.85 \pm 0.08}$ & & $\frac{1.54 \pm 0.19}{2.23 \pm 0.07}$ & 一 & $\frac{0.03 \pm 0.01}{0.07 \pm 0.00}$ & - \\
\hline $\begin{array}{l}\text { Zone of strong } \\
\text { contamination }\end{array}$ & $\begin{array}{l}\frac{1.24 \pm 0.11}{*} \\
\frac{*}{3.03 \pm 0.37} \\
*\end{array}$ & $\frac{2.36}{3.81}$ & $\begin{array}{l}\frac{1.00 \pm 0.03}{\frac{*}{-}} \\
2.37 \pm 0.04 \\
*\end{array}$ & $\frac{3.89}{2.78}$ & $\frac{2.06 \pm 0.21}{3.03 \pm 0.03 *}$ & $\begin{array}{l}\underline{4}^{\underline{1.3}} \\
6^{1.3} \\
\end{array}$ & $\begin{array}{l}\frac{0.20 \pm 0.01}{*} \\
\frac{*}{0.40 \pm 0.01} \\
\quad *\end{array}$ & $\frac{6.15}{5.37}$ \\
\hline \multicolumn{9}{|c|}{ Sorbus aucuparia L. } \\
\hline Control & $\frac{0.15 \pm 0.02}{0.69 \pm 0.01}$ & & $\frac{0.41 \pm 0.02}{0.71 \pm 0.04}$ & & $\frac{1.34 \pm 0.08}{1.68 \pm 0.00}$ & & $\frac{0.03 \pm 0.00}{0.08 \pm 0.00}$ & \\
\hline $\begin{array}{l}\text { Zone of strong } \\
\text { contamination }\end{array}$ & $\begin{array}{l}\frac{5.00 \pm 0.60}{*} \\
\frac{*}{8.15 \pm 0.24} \\
*\end{array}$ & $\begin{array}{l}\underline{33.5} \\
\underline{1} \\
11.7 \\
9\end{array}$ & $\begin{array}{l}\frac{1.79 \pm 0.10}{*} \\
\frac{*}{2.12 \pm 0.07} \\
*\end{array}$ & $\frac{4.33}{2.97}$ & $\frac{2.15 \pm 0.09^{*}}{4.95 \pm 0.07^{*}}$ & $\begin{array}{l}\underline{1.6} \\
\underline{0} \\
2.9 \\
4\end{array}$ & $\begin{array}{l}\frac{0.23 \pm 0.02}{*} \\
\frac{*}{0.35 \pm 0.00} \\
\quad *\end{array}$ & $\frac{8.81}{4.63}$ \\
\hline \multicolumn{9}{|c|}{ Aesculus hippocastanum $\mathrm{L}$. } \\
\hline Control & $\underline{0.20 \pm 0.02}$ & - & $\underline{0.05 \pm 0.00}$ & - & $\underline{0.44 \pm 0.02}$ & - & $\underline{0.05 \pm 0.00}$ & - \\
\hline
\end{tabular}




\begin{tabular}{|c|c|c|c|c|c|c|c|c|}
\hline & $0.27 \pm 0.00$ & & $0.30 \pm 0.01$ & & $1.15 \pm 0.16$ & & $0.07 \pm 0.00$ & \\
\hline $\begin{array}{l}\text { Zone of strong } \\
\text { contamination }\end{array}$ & $\begin{array}{l}\underline{0.36 \pm 0.02} \\
\frac{*}{-} \\
1.21 \pm 0.07 \\
*\end{array}$ & $\frac{1.79}{4.55}$ & $\begin{array}{l}\frac{1.10 \pm 0.09}{*} \\
\frac{*}{-} .08 \pm 0.01 \\
*\end{array}$ & $\begin{array}{l}\frac{23.2}{7} \\
7.01\end{array}$ & $\frac{0.93 \pm 0.02 *}{2.24 \pm 0.03 *}$ & $\begin{array}{l}\underline{2.1} \\
\underline{1} \\
7\end{array}$ & $\begin{array}{l}\underline{0.16 \pm 0.02} \\
\frac{*}{-} \\
0.37 \pm 0.00 \\
*\end{array}$ & $\frac{3.47}{5.55}$ \\
\hline \multicolumn{9}{|c|}{ Betula pendula Roth } \\
\hline Control & $\frac{0.39 \pm 0.03}{0.88 \pm 0.01}$ & - & $\frac{0.93 \pm 0.04}{1.06 \pm 0.04}$ & - & $\frac{0.70 \pm 0.00}{1.76 \pm 0.08}$ & - & $\underline{0.08 \pm 0.00}$ & - \\
\hline $\begin{array}{l}\text { Zone of strong } \\
\text { contamination }\end{array}$ & $\begin{array}{l}\frac{0.75 \pm 0.03}{*} \\
\frac{*}{-} \\
\quad * 0.05 \pm \\
*\end{array}$ & $\frac{1.95}{2.32}$ & $\begin{array}{l}\frac{1.25 \pm 0.11}{*} \\
\frac{*}{1.52 \pm 0.04} \\
*\end{array}$ & $\frac{1.34}{1.43}$ & $\frac{1.43 \pm 0.08 *}{4.59 \pm 0.22 *}$ & $\begin{array}{l}\underline{5}^{2.0} \\
2.6\end{array}$ & $\begin{array}{l}\frac{1.16 \pm 0.01}{*} \\
\frac{*}{0.62 \pm 0.02} \\
*\end{array}$ & $\begin{array}{l}\frac{15.0}{3} \\
5.79\end{array}$ \\
\hline
\end{tabular}

Note. ICI is the inter-tissue contamination index of leaves; $*$ - statistically reliable difference in relation to control after $p<0.05$; where the numerator is the value in the phase of complete isolation of leaf, and the denominator is the phase of completion of leaf growth

Therefore the exact content of TBA-active connections is an important index of different factors influencing degree on the organism. It is interesting to study that which allows to a certain extent to estimate the functional state of organism and its hetero-specific adaptation ability (Bishnoi et al.,1993; Finkel- Holbrook, 2000; Naoharu et al., 2003; Tang-Xi, 2002; Wang, 2004).

The data of the content of TBA-active products testifies the practically identical motion of lipids peroxidation processes (fig.) in the leaves of arboreal plants which grow in the arboretum, that all of the probed species in both phases of leaves morphogenesis. Most intensively lipid peroxidation passes in the assimilative organs of Betula pendula Roth, Sorbus aucuparia L. and Tilia cordata Mill., that, to our opinion, explained the considerable high biological accumulation of $\mathrm{Ni}$ and $\mathrm{Cd}$. However necessary to take into account at the discussion of findings, that there are differences in the species-specificity of free-radical peroxidation development.

Figure 1: Content of TBA-active products in the leaves of arboreal plants $\left(10^{-6} \mathrm{M}\right.$ of malonyl dyaldehyde $\left.\mathrm{mg}^{-1} \mathrm{proteine}\right)$ in the phase of complete isolation of leaf (a) and phase of completion of leaf growth (b)

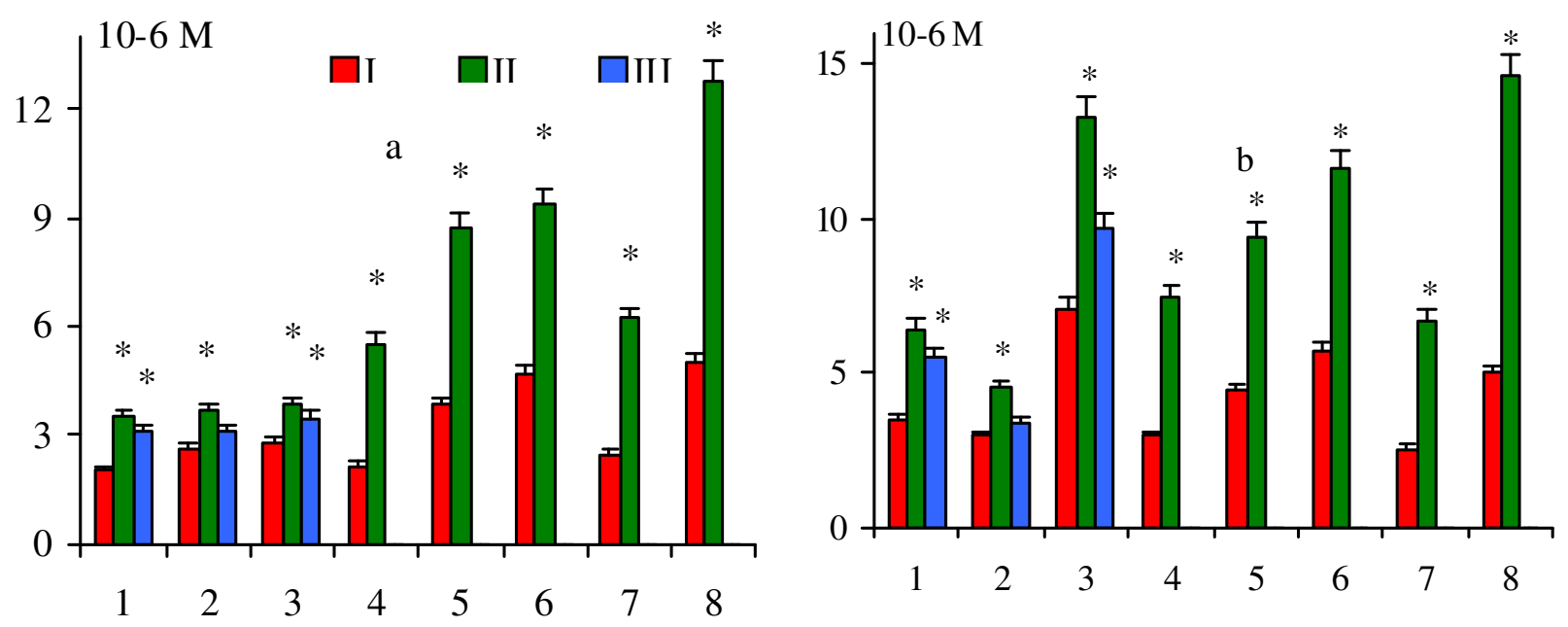

I - control; II - area of strong contamination on «Red Lead Factory» LTD; III -area of low contamination on «Red Lead Factory» LTD; 1 - Populus bolleana Lauche; 2 - Populus italica (Du Roi) Moench; 3 - Acer negundo L.; 4 - Picea pungens Engelm.; 5 - Tilia cordata Mill.; 6 - Sorbus aucuparia L.; 7 - Aesculus hippocastanum L.; 8 - Betula pendula Roth;* - statistically reliable difference in relation to control after $p<0.05$

Information can be presented on figure 1. It testify, that the amount of peroxidation after-products in the assimilatory process of arboreal plants at the terms of strong and weak contamination zone on «Red Lead Factory» LTD exceeds their maintenance in control plants in both phases of leaves' development. For example, in the assimilatory organs of Populus bolleana Lauche in the strong contamination zone in the phase of complete isolation of leave TBA-active product content was $70 \%$, and in the weak contamination zone was only $50 \%$ compare to control. In the phase of completion of leaf growth this index increased to $83 \%$ and $57 \%$ accordingly. As compared to control plants for Populus italica (Du Roi) Moench the specific increase of lipid peroxidation after-products content was $40 \%$ and $17 \%$ in leaves (phase of complete isolation of leave) and $52 \%$ and $14 \%$ (phase of completion of growth) accordingly. 
The results show that for species with the greatest phyto-extraction potential, namely Populus bolleana Lauche and Populus italica (Du Roi) Moench, characteristically low level of free-radical processes are not exceed this index at the control plants more than in 1.9 times (fig.1). To our opinion such results can be explained with the significant intensity of antioxidant systems functioning at the noted species, which is because of the greater stability in the conditions of technogen influence. We have to note that at a certain phytoextraction potential, next to the considerable inter-tissue contamination index of leaves, there is growth of TBAactive compound content. Regarding the Tilia cordata Mill., (species has middle-level coefficient of biological accumulation) characteristically analogical to the above-mentioned tendency, the increase of peroxidation afterproducts content. However, it is necessary to mark, that at the Acer negundo L., which also belongs to this group of arboreal plants, in the phase of complete isolation of leaves there is the insignificant activating of lipid peroxidation processes and, opposite, in the phase of completion of leave growth and ripening - intensification of free-radical processes is swiftly increased.

The most substantial increase of TBA-active content of compounds (more, than in 2.5 times) is peculiar for a Betula pendula Roth, Aesculus hippocastanum L. and Picea pungens Engelm., at a middle level and regards to the $\mathrm{Zn}, \mathrm{Ni}, \mathrm{Pb}$ and $\mathrm{Cd}$ accumulation in the different industrial contamination zones.

\section{CONCLUSIONS}

The parklands are artificially created area in the zones of industrial enterprise. Because of the substantial anthropogenic influence, several physiological and biochemical changes take place in plants, so it is determined by a certificate what species can be grown. It is set that in the swingeing majority of species of arboreal plants with high heavy metal accumulation level there is low content of peroxidation after-products in assimilatory organs, it is due to their properties in greater adjustment in the conditions of industrial contamination zone. An exception is made by the Picea pungens Engelm., what under industrial pollutants significant increase of freeradical processes intensity was measured. From other side it means, that even insignificant maintenance of heavy metals in the assimilatory vehicle of plant with the middle level of this pollutants accumulation results the lipid peroxidation intensification, the growth of TBA-active product concentration was 2.5 times more compare to control plants.

\section{REFERENCES}

Bishnoi N.R., Sheoran I.S., Singh Randhir.(1993): Influence of cadmium and nickel on photosynthesis and water relations in wheat leaves of different insertion level // Photosynthetica 28, № 3. - p. 473-479.

Dospekhov B.A. (1985): Method of the field experience (with bases of statistical treatment of results of researches). - Moskow: Agropromizdat, p.351.

Finkel T., Holbrook N.J.(2000): Oxidants, oxidative stress and the biology of aging // Nature. 408. p. 239-247.

Garcia A., Baquedano F.J., Navarro P., Castillo F.J.(1999): Oxidative stress induced by copper in sunflower plants // Free Rad. Res. 31. p. $51-57$

Greenberg Ch.S., Gaddock Rh.R.(1982): Rapid single step membrane proteine assay // Clin. Chem. 28, N 7. - p. $1726-1728$.

Ground-geochemical inspection of the urbanized territories. Methodical recommendations / Compilers: Balyuk S.A., Fadeev A.I.,

Miroshnichenko M.M. - Kharkov: «nstitute the name of O.N. Sokolovskogo» Ukraine Academy of Agrarian Sciences - 2004. - p.54.

Kabata-Pendias A., Pendias H.(2001): Trace elements in soils and plants. - N. Y.: CRC Press, 432 p.

Kamishnikov V.C. (2000): Reference book on clinical-biochemical laboratory diagnostics. - Minsk.: Byelorussia

Karperts Yu.V., Kolupaev Yu.Ye. (2008): The participation of reactive oxygen species in the plants heat resistance induction at the short-term hardening by superoptimum temperatures // Bioecological problems and means of solution. Materials of Int. conf. (Saransk, Russia, 15-18 May 2008). - Saransk, 2008. - P. 202-203.

Kosyk O., Okanenco A., Batsmanova L., Taran N. Yu. (2006):Wheat glycolipid changes while lead ion action // Book of Publications XXXVI Annual Meeting European Society for New Methods in Agricultural Research (ESNA), Jasi, Romania. - 2006. - P. 533-540.

Lichtanthaler H.K. (1998): To stress concept in plants: An introduction // Stress of Life: Ann. N.Y. Acad. Sci. 851. p. 187-198.

Feldman C. (1974): Perchloric acid procedure for wetashing organics for the determination of mercury (and other metals). Anal. Chem., 46. 1606-1609.

Mishra A., Choudhuri M.A. (1999): Effects of salicylic acid on heavy metal-induced membrane deterioration mediated by lipoxygenase in rice // Biol. Plant. 42, N 3. - p. 409-415.

Mizuno Naoharu, Nosaka Shiro, Mizuno Takafumi, Horie Kenji, Obata Hitoshi (2003): Distribution of Ni and Zn in the leaves of Thlaspi japonicum growing on ultramafic soil // Soil Sci. and Plant Nutr. 49, № 1. - p. 93-97.

Olsson M. (1994): Plant lipids - effect of aging and drought stress // University of Goteborg. - Goteborg, Sweden. p. 117-129.

Briat Jean-Francois, Lebrun Michel (1999): Plant responses to metal toxiti // C. r. Acad. Sci. Ser. 3, 322, № 1. - p. 43-54.

Tang Shi-rong, Xi Lei.(2002): Accumulation of chromium by Commelina communis L. grown in solution with different concentrations of $\mathrm{Cr}$ and L-histidine // J. Zhejiang Univ. Sci 3, № 2. - p. 232-236.

Wang X. (2004): Lipid signalling // Curr. Opin. Plant Biol. 7. p. 329-336. 